\title{
1310 nm Source Spectral-Domain Optical Coherence Tomography for Chinese Pigment and Jadeite Research
}

\author{
Hao Sun1, Tingting Gang2, Manli Hu², Nan Liu², Rongxin Tong², Xiaobo Liu², Qunxi Zhang33, \\ Jianhong Zhou ${ }^{4}$ \\ ${ }^{1}$ School of Physics and Optoelectronic Engineering, Xidian University, Xi'an, China \\ ${ }^{2}$ School of Physics, Northwest University, Xi'an, China \\ ${ }^{3}$ Shaanxi History Museum, Xi'an, China \\ ${ }^{4}$ School of cultural heritage, Northwest University, Xi'an, China \\ Email: "huml@nwu.edu.cn
}

Received 29 April 2016; accepted 20 August 2016; published 25 August 2016

\begin{abstract}
Optical Coherence Tomography (OCT) technique is a nondestructive optical detection technology based on low-coherence interferometer and it has become an attractive cultural heritage research method. A $1310 \mathrm{~nm}$ source spectral-domain optical coherence tomography (SD-OCT) system based on optical fiber Michelson interferometer and optical spectrum analyzer is proposed and demonstrated for Chinese cultural heritage research. The cross-section OCT images of Chinese pigment samples and jadeite samples can provide a lot of valuable microstructure information for the Chinese cultural heritage research and identification works.
\end{abstract}

Keywords

Optical Coherence Tomography, Spectral-Domain OCT, Cultural Heritage

\section{Introduction}

Optical coherence tomography technology was first proposed in 1991 by D. Huang et al. [1], and was used in ophthalmology clinical medical research in 1995. Subsequently, OCT technology got extensive applications in fund of biopsy, oral imaging, dental caries and skin tissues imaging [2]-[4]. In the past ten years, OCT technique researching progress is rapid, its resolution, scanning speed and imaging depth have been greatly improved, and successively developed frequency-domain OCT, Doppler OCT and polarization sensitive OCT. With the growing maturity in medical diagnosis application, researchers expanded the application range of OCT Technology gradually to industrial inspection and artwork research.

From 2004, OCT technology began to be used for surface structure imaging detection of jade [5], ceramic [6] [7] and painting [8]. Especially, researchers obtained many achievements in the study of western painting com-

${ }^{*}$ Corresponding author.

How to cite this paper: Sun, H., Gang, T.T., Hu, M.L., Liu, N., Tong, R.X., Liu, X.B., Zhang, Q.X. and Zhou, J.H. (2016) 1310 nm Source Spectral-Domain Optical Coherence Tomography for Chinese Pigment and Jadeite Research. Optics and Photonics Journal, 6, 48-52. http://dx.doi.org/10.4236/opj.2016.68B009 
pared with the traditional microscopic imaging technology. The varnish and paint layers of western painting can be distinguished easily according to their OCT images of cross sections [9]. The axial resolution of painting's OCT images reached about 10 microns, and the detecting depth was up to 400 microns. OCT imaging has been used to solve the detection problem of under-drawing under the subsurface such as varnishes and glazes due to the ability that OCT can obtain microstructure information [10]. And Liang et al. reported the first application of in situ OCT imaging on wall paintings combined OCT technology and hyper-spectral imaging technology [11].

In this paper, an SD-OCT system with the central wavelength of $1310 \mathrm{~nm}$ is proposed for Chinese cultural heritage research. This SD-OCT system used long wavelength light source and high resolution spectrometer can reach a larger detection depth and display the microstructure information of Chinese pigment samples and jadeite samples clearly. The cross-section OCT images demonstrate that the OCT technology can be used to research the polychrome cultural relics and authenticate authenticity of jadeite products effectively.

\section{Experimental Setup and Principle}

The schematic diagram of this SD-OCT system is shown in Figure 1. This all-fiber OCT system consists of five major components, super luminescent diode (SLD) light source, Michelson interferometer, CCD spectrometer, objective probe with $3 \times$ focusing lens and a computer with control circuits. Light emitted from the SLD enters the $2 \times 2$ 20:80 fiber coupler, where it is split into two beams and travel along the reference arm and sample arm respectively. The $2 \mathrm{D}$ galvo mirror is used for scanning driver module.

The center wavelength of SLD light source is $1310 \mathrm{~nm}$ and the full width half maximum (FWHM) is $60 \mathrm{~nm}$. The resolution of the used spectrometer is $0.06 \mathrm{~nm}$. The theoretical axial resolution $(\Delta \mathrm{z})$ and imaging depth $\left(\mathrm{z}_{\max }\right)$ of the SD-OCT can be calculated according to the formulas:

$$
\begin{gathered}
\Delta \mathrm{z}=\frac{2 \ln 2}{\pi} \frac{\lambda_{0}^{2}}{\Delta \lambda} \\
z_{\max }=\frac{\lambda_{0}^{2}}{4 \delta \lambda} \frac{1}{n}
\end{gathered}
$$

where the $\lambda_{0}, \Delta \lambda, \delta \lambda$ and $\mathrm{n}$ are the center wavelength, FWHM of light source, wavelength resolution of spectrometer and refractive index of the sample, respectively. Thus the axial resolution in air is calculated about $12.6 \mu \mathrm{m}$ and the imaging depth is $7.15 \mathrm{~mm}$. Assuming that the refractive index of jadeite materials is $\sim 1.66$, the theoretical imaging depth in jadeite objects is about $4.3 \mathrm{~mm}$. But in practical application, the imaging depth is usually within one millimeter due to the differences of absorption and scattering characteristics of target materials with respect to air and biological tissues. The transparency of the target material can also affect the detection depth of OCT system.

\section{Results and Analysis}

The SD-OCT system of Figure 1 was constructed in the laboratory and the drive and control program was written by LabVIEW software. The application of SD-OCT in Chinese cultural heritage research was demonstrated by testing some Chinese pigment samples and jadeite beads.

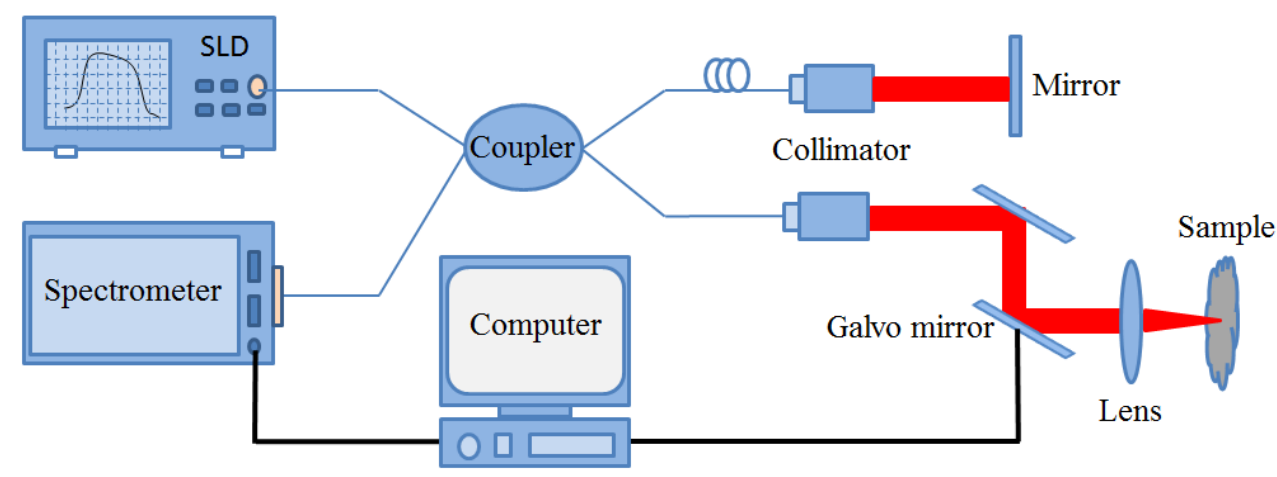

Figure 1. The schematic diagram of SD-OCT system. 
The pigment samples were made by painting the commonly used pigments on the glass slides. After days of natural drying, the pigment layers appeared the phenomenon of cracking, detachment and swell. This is similar to the actual situations of old murals and paintings. These pigment samples can be used to simulate the real cultural relics with pigment layers. After the imaging test of nearly 20 kinds of pigment samples, it was found out that the $1310 \mathrm{~nm}$ source SD-OCT system could get clear images of subsurface microstructure of the pigment samples. Figures 2-4 show the representative azurite, gamboges and ochre samples and their cross-section OCT images (red line position), respectively.

Figure 2(b) shows the cross-section OCT image of the broken location of azurite sample where the pigment layer, transparent glass layer, air layer and nethermost objective table can be distinguished clearly. But the OCT image of gamboge sample in Figure 3(b) is different from Figure 2(b). Compared to the clear Figure 2(b), the left and right of Figure 3(b) have a slight dislocation in vertical direction. This is the result of OCT image representing only the optical path length rather than the true physical depth. Due to the higher refractive index of gamboge sample, the higher optical path length induces the dislocation in vertical direction. The white line with red arrow mark in Figure 3(b) should be the mirror image of the lower surface of glass. The right half ochre sample in Figure 4(a) was painted a second layer of ochre pigment and thus the right ochre pigment was thicker than left. The thick pigment layer can be seen clearly in the OCT image in Figure 4(b). From these cross-section OCT images in Figures 2-4, we can find out that the OCT technology can be used to research the polychrome cultural relics effectively.

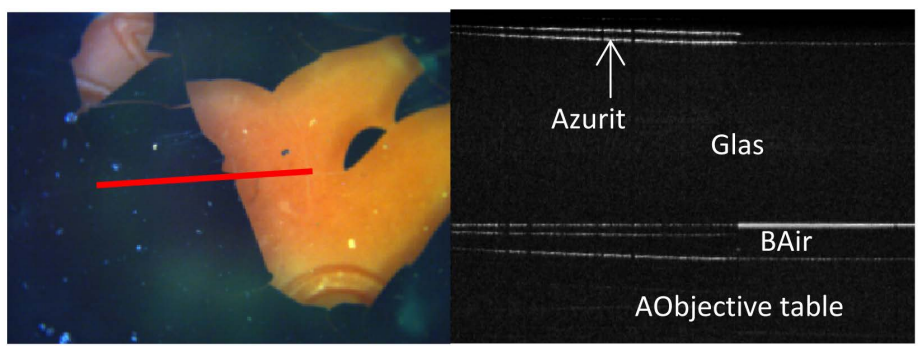

(a)

(b)

Figure 2. Azurite sample and its cross-section OCT image.

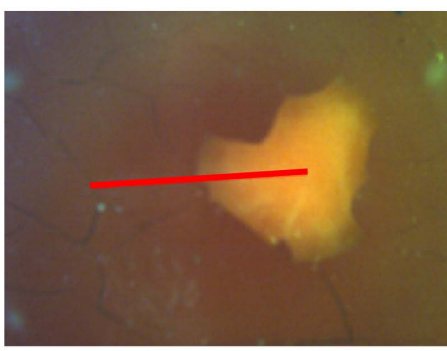

(a)

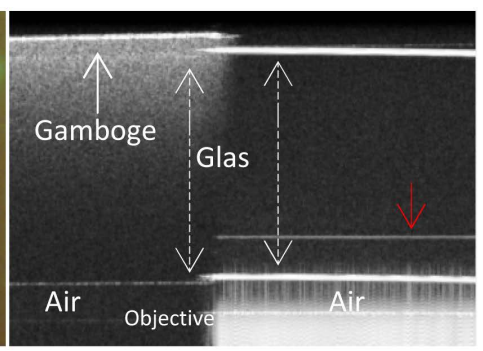

(b)

Figure 3. Gamboge sample and its cross-section OCT image.

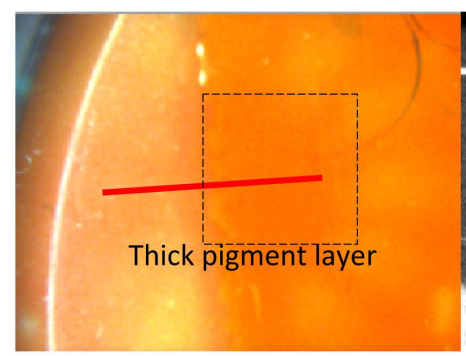

(a)

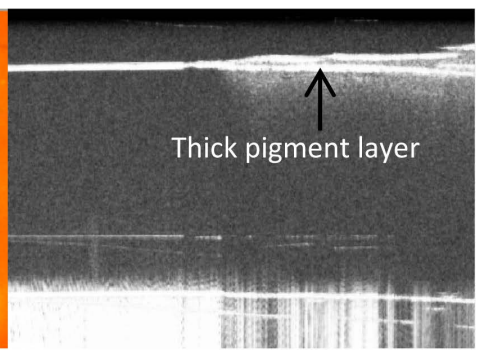

(b)

Figure 4. Ochre sample and its cross-section OCT image. 
Besides the pigment samples, a real jadeite bead and a fake jadeite bead were selected to be tested via OCT imaging method for comparison and analysis (as shown in Figure $\mathbf{5}$ and Figure 6). In general, it is hard to distinguish which one is false just depend on observation via human eyes or magnifying glass. The fake jadeite manufactured by the modern technology method used compressed stone powder and glue injection processing is almost convincing. Jadeite is a kind of jade and is known as the "oriental gem" due to its expensive and precious characteristics. China has plenty of ancient jadeite cultural relics, and most of them were beautifully designed and great valuable. Thus the antique collection markets appear a lot of fake jadeites. The authenticity identification of jadeites is increasingly important.

It can be seen that the two cross-section OCT images of the real and fake jadeite beads (red line position) have obvious difference in Figure 5(b) and Figure 6(b). The jadeite bead of Figure 5(a) is carved by using natural stone material. Its cross-section OCT image in Figure 5(b) shows the mineral structure of natural jadeite. The dark stripes in vertical direction (A and B with red arrow mark) are caused by strong absorbing particles, which are some granular impurities embedded in the high scattering jadeite material. Comparing the Figure 5(b) and Figure 6(b), the special layered structure of the fake jadeite made of glue injection processing is obvious different with the subsurface microstructure of real jadeite. Consequently, the OCT imaging method can be used for authenticating authenticity of jadeite products.

\section{Conclusion}

A $1310 \mathrm{~nm}$ source SD-OCT system and its application research in Chinese cultural heritage are proposed and demonstrated. We got the subsurface microstructure OCT images of the Chinese pigment samples and jadeite bead samples. These high resolution OCT images can display the valuable microstructure information clearly and auxiliary appraisal authenticity. Consequently, the OCT technology can be a good method for Chinese cultural heritage research.

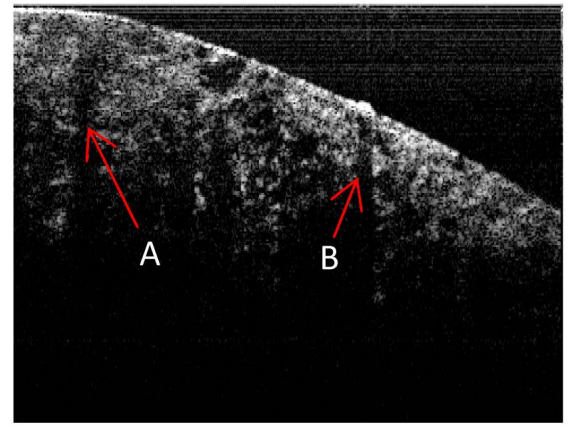

(a)

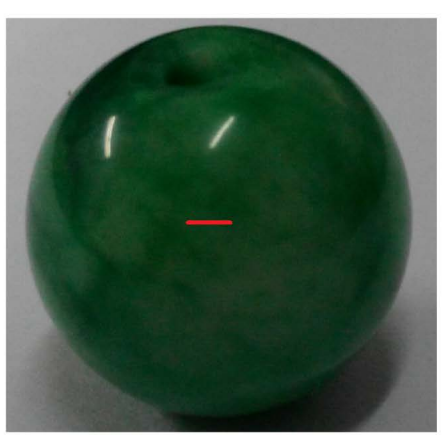

(b)

Figure 5. A real jadeite bead and its cross-section OCT image.

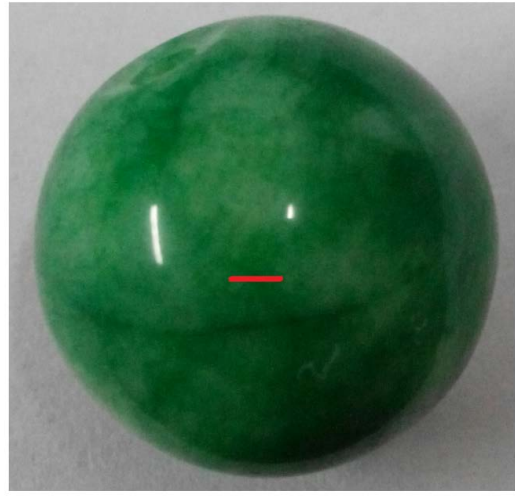

(a)

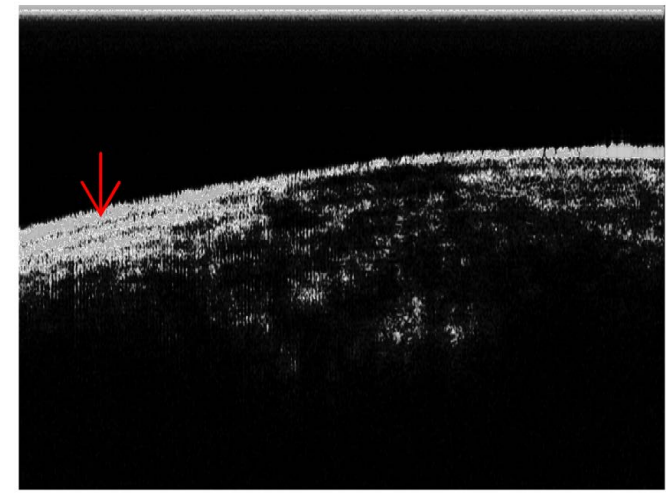

(b)

Figure 6. A fake jadeite bead and its cross-section OCT image. 


\section{Acknowledgements}

This work was supported by the National Natural Science Foundation of China (61377087), the National Key Technology Support Program (2013BAH49F03) and the Northwest University Postgraduate Innovative Talents Training Project (YZZ15087, YJG14001 and YZZ14103).

\section{References}

[1] Huang, D., Swanson, E.A., Lin, C.P., Schuman, J.S., Stinson, W.G., Chang, W., Hee, M.R., Flotte, T., Gregory, K. and Puliafito, C.A. (1991) System for Optical Coherence Tomography. Science, 254, 1178-1181. http://dx.doi.org/10.1126/science.1957169

[2] Fercher, A.F., Drexler, W., Hitzenberger, C.K. and Lasser, T. (2003) Optical Coherence Tomography Principles and Applications. Review of Laser Engineering, 31, 635-642. http://dx.doi.org/10.2184/lsj.31.635

[3] Colston, B.W., Sathyam, U.S., Da Silva, L.B., Everett, M.J., Stroeve, P. and Otis, L. (1998) Dental OCT. Opt. Express, 3, 230-238. http://dx.doi.org/10.1364/OE.3.000230

[4] Tearney, G.J., Bouma, B.E., Boppart, S.A., Golubovic, B., Swanson, E.A. and Fujimoto, J.G. (1996) Rapid Acquisition of in Vivo Biological Images by use Of Optical Coherence Tomography. Opt. Lett, 21, 1408-1410. http://dx.doi.org/10.1364/OL.21.001408

[5] Yang, M.L., Lu, C.W., Hsu, I.J. and Yang, C.C. (2004) The Use of Optical Coherence Tomography for Monitoring the Subsurface Morphologies of Archaic Jades. Archaeometry, 46, 171-182. http://dx.doi.org/10.1111/j.1475-4754.2004.00151.x

[6] Targowski, P. and Kowalczyk, A. (2004) The Application of Optical Coherence Tomography to Non-Destructive Examination of Museum Objects. Studies in Conservation, 49, 107-114.

[7] Liang, H., Sax, M., Saunders, D. and Tite, M. (2012) Optical Coherence Tomography for the Non-invasive Investigation of the Microstructure of Ancient Egyptian Faience. J.Archaeol, 39, 3683-3690. http://dx.doi.org/10.1016/j.jas.2012.06.007

[8] Hughes, M., Spring, M. and Podoleanu, A. (2010) Speckle Noise Reduction in Optical Coherence Tomography of Paint Layers. Appl. Opt, 49, 99-107. http://dx.doi.org/10.1364/AO.49.000099

[9] Liang, H., Cid, M., Cucu, R., Dobre, G., Podoleanu, A., Pedro, J. and Saunders, D. (2005) En-Face Optical Coherence Tomography-A Novel Application of Non-Invasive Imaging to Art Conservation. Opt. Express, 13, 6133-6144. http://dx.doi.org/10.1364/OPEX.13.006133

[10] Targowski, P., Rouba, B., Gora, M., Tyminska-widmer, L., Marczak, J. and Kowalczyk, A. (2008) Optical Coherence Tomography in Art Diagnostics and Restoration. Appl. Phys. A, 92, 1-91. http://dx.doi.org/10.1007/s00339-008-4446-x

[11] Liang, H., Lange, R., Howard, H. and Spooner, J. (2011) Non-Invasive Investigations of a Wall Painting Using Optical Coherence tomography and Hyperspectral Imaging. Proc. of SPIE, 8084, 143-151. http://dx.doi.org/10.1117/12.890088

\section{Submit or recommend next manuscript to SCIRP and we will provide best service for you:}

Accepting pre-submission inquiries through Email, Facebook, LinkedIn, Twitter, etc.

A wide selection of journals (inclusive of 9 subjects, more than 200 journals)

Providing 24-hour high-quality service

User-friendly online submission system

Fair and swift peer-review system

Efficient typesetting and proofreading procedure

Display of the result of downloads and visits, as well as the number of cited articles

Maximum dissemination of your research work

Submit your manuscript at: http://papersubmission.scirp.org/ 